\title{
Fetal valproate syndrome
}

\author{
J Clayton-Smith, D Donnai
}

There is an increased incidence of major and minor congenital abnormalities in infants born to epileptic mothers (6 to $7 \%$ compared with 2 to $3 \%$ in the general population). ${ }^{1}$ Factors which may contribute to this include the occurrence of seizures leading to periods of hypoxia during pregnancy, an inherited predisposition to malformations owing to intrinsic maternal factors, and the teratogenic effects of anticonvulsants. Congenital malformations following intrauterine exposure to phenytoin are well documented, ${ }^{2}$ but more recently a teratogenic effect has been observed in humans after maternal sodium valproate therapy. ${ }^{3-6}$ Sodium valproate is a salt of dipropyl acetic acid which is conjugated in the liver and has a short half life. It is thought to act either by inhibiting $\gamma$-aminobutyric acid metabolism or by a direct effect on mitochondria, thereby impairing cellular energy metabolism. ${ }^{7}$ It is a popular drug because of its broad range of anticonvulsant effects and relative freedom from sedative and behavioural effects. It is 80 to $90 \%$ bound to plasma proteins and may displace other drugs if used in combination, giving rise to toxicity. It may also interact with other drugs metabolised by the liver, for example, phenobarbitone. Long term valproate therapy may lead to carnitine depletion which impairs mitochondrial fatty acid metabolism and leads to hepatotoxicity. ${ }^{8}$ This effect is seen mainly in children. There is no clear relationship between serum concentrations and anticonvulsant effects, and although increasing doses are required during pregnancy to keep patients seizure free, it is generally accepted that the lowest dose at which the patient is seizure free should be used, even if this does not fall within the recommended therapeutic range of 50 to $100 \mu \mathrm{g} / \mathrm{ml}$. Valproic acid crosses the placenta and is present in a higher concentration in the fetus than in the mother.

Sodium valproate was licensed for use in 1978, and the first adverse report of a fetus exposed to the drug was published in $1980 .^{9}$ Other reports have followed, documenting similar patterns of minor and major malformations. Particular attention has been drawn to the occurrence of neural tube defects in infants exposed to valproate in utero. ${ }^{10-12}$ A summary of the clinical features of the "fetal valproate syndrome" (FVS) is documented below.

\section{Natural history}

Pregnancy usually proceeds uneventfully and there is no increased incidence of instrumental delivery or birth asphyxia; $10 \%$ of babies are small for gestational age. Withdrawal symptoms during the neonatal period are extremely common. ${ }^{13}$ The most frequent of these are irritability, jitteriness, hypotonia, and seizures, typically occurring between 12 and 48 hours. They appear to be dose related. Feeding problems often ensue.

Data on long term follow up of these infants are scanty but postnatal growth appears to be normal. Microcephaly tends only to occur in those infants also exposed to other anticonvulsants. General health is good and not all children with FVS will be drawn to the attention of the paediatrician during the first year of life. Ardinger et $a l,{ }^{6}$ however, reviewed the clinical features in 15 cases of FVS presenting with dysmorphic features and found evidence of mild to moderate developmental delay or neurological abnormality in $10(67 \%)$ on follow up. The association of developmental delay with valproate exposure has been confirmed in another report ${ }^{3}$ and also correlates with our own personal experience. Longer term effects have not yet been documented because of the relatively recent introduction of the drug.

\section{Facial features}

The facial features are listed in table 1. In combination they give rise to a distinctive facial phenotype which was commented upon by DiLiberti et $a l^{\beta}$ and by Winter et al. ${ }^{5}$ The patients in figs 1 and 2 show these typical facial features, which tend to evolve with age. The nasal root

\section{Table 1 Facial features seen in fetal valproate syndrome}

Trigonocephaly

Tall forehead with bifrontal narrowing

Epicanthic folds

Infraorbital groove

Medial deficiency of eyebrows

Flat nasal bridge

Broad nasal root

Anteverted nares

Shallow philtrum

Long upper lip with thin vermilion border

Thick lower lip

Small, downturned mouth 


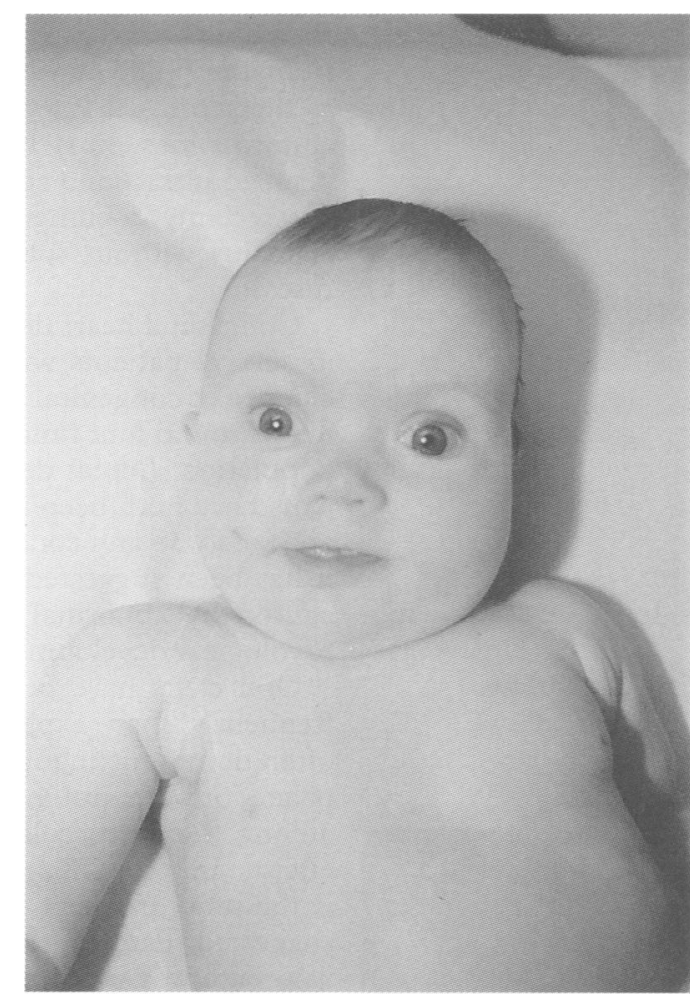

Figure 1 Typical facial features of FVS in an infant. Note trigonocephaly, epicanthic folds, and infraorbital grooves.

\section{Table 2 Congenital malformations associated with FVS}

Neural tube defects

Congenital heart diseas

Cleft lip and palate

Genitourinary malformations

Tracheomalacia

Radial ray defects

Arachnodactyly/overlapping digits

Abdominal wall defects

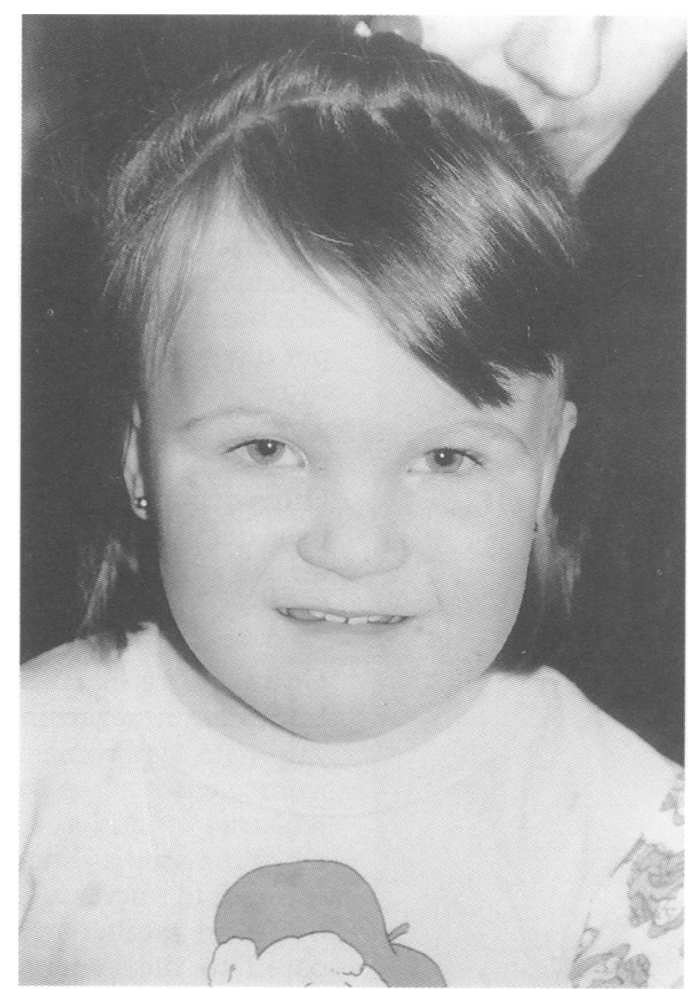

Figure 2 Facial features in a 3 year old with broad, flat nasal bridge, arched eyebrows, and downturned mouth with thin vermilion border to upper lip.

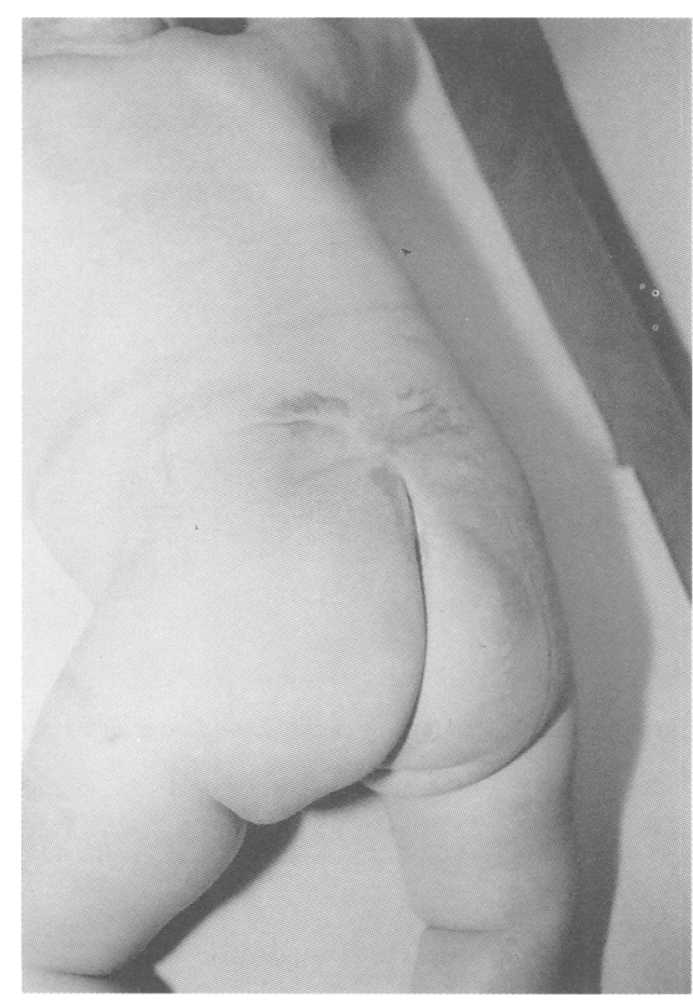

Figure 3 Neural tube defects are often skin covered and usually involve the sacral region.

is broad and epicanthic folds continue inferiorly to connect with an infraorbital crease or groove. The appearance of the mouth and upper lip are particularly characteristic and the philtral pillars are often indistinct. Many authors have commented upon abnormal modelling of the ears but there does not appear to be any specific ear abnormality among the various reports.

\section{Congenital malformations}

These are listed in table 2 . The most frequent major congenital malformations are neural tube defects, congenital heart defects, oral clefts, genital abnormalities, and limb defects. Other less frequent abnormalities include abdominal wall defects, tracheomalacia, and strabismus. There has been one reported case of congenital liver disease but this may well have been unrelated to the valproate therapy. ${ }^{14}$ Neural tube defects have been estimated to occur at around 10 times the normal incidence in fetuses exposed to valproate and appear to be specifically related to valproate therapy rather than to other anticonvulsants. ${ }^{615}$ Most reports have been of spina bifida rather than anencephaly and there is a predisposition for very low lumbar or sacral defects (fig 3 ) suggesting that valproate affects primarily the lowest closure site of the neural tube. ${ }^{16}$ It has been postulated that defects at this site may be the result of defective canalisation of the neural tube rather than neurulation defects. Zinc deficiency has been suggested as a possible cause of NTDs associated with valproate exposure as sodium valproate readily binds zinc and NTDs have been reported both in infants of mothers with acrodermatitis enteropathica and in offspring of zinc deficient rats. ${ }^{17.18} \mathrm{It}$ is interesting to note that the defects observed in 


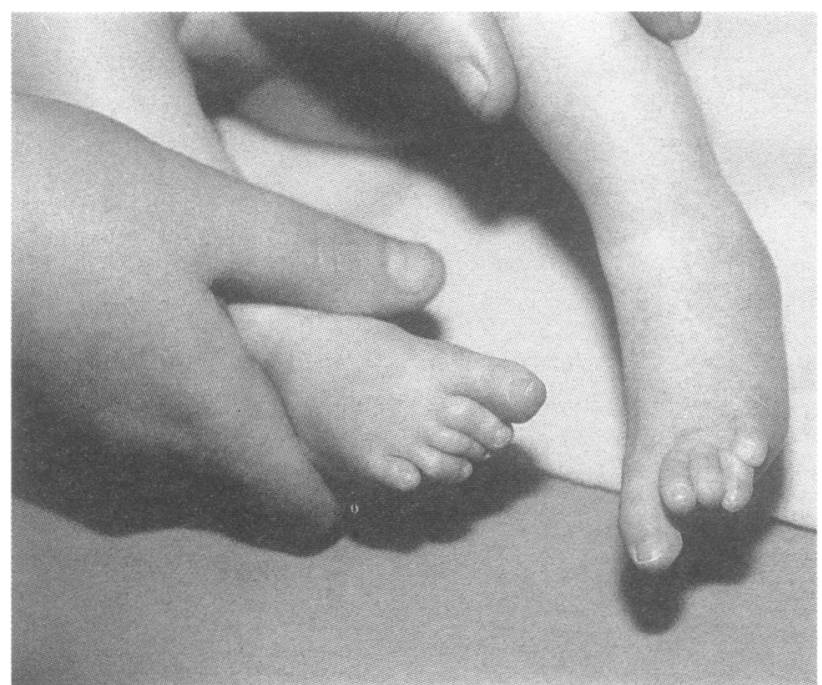

Figure 4 Long, overlapping toes in an infant with FVS.

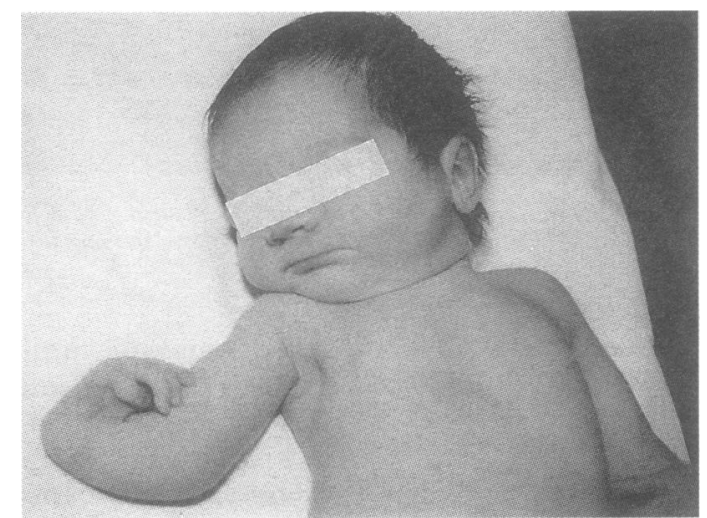

Figure 5 Radial ray defect in an affected neonate.

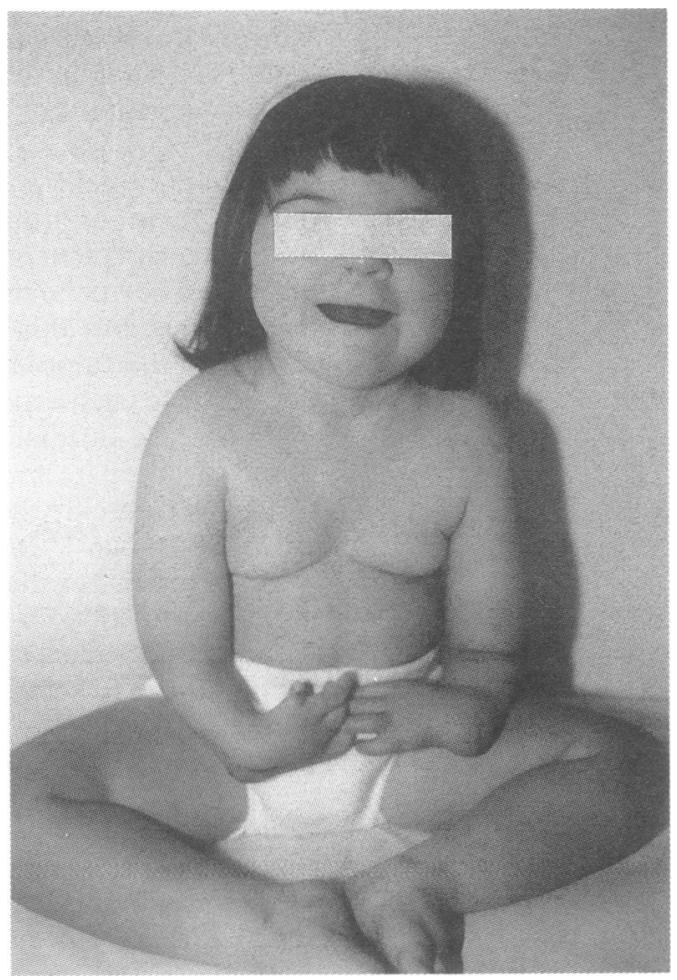

Figure 6 Bilateral radial ray defects in sib of patient in fig 5.
FVS are often skin covered. This is significant from the point of view of prenatal diagnosis, as the serum AFP level is often normal so the abnormalities must be sought specifically by detailed ultrasound scanning. Martinez-Frias ${ }^{15}$ has recently documented two cases of hydrocephalus without spina bifida in exposed fetuses.

Congenital heart defects have been reported in several patients with FVS ${ }^{23616}$ and the incidence of congenital heart disease is estimated to be around four times that seen in the general population. Septal defects and valvular problems have both been reported. There does not appear to be any consistent type of defect but it has been suggested that the defects may be caused by abnormal blood flow during embryological development.

Oral clefts have been seen five times more frequently than expected. Published reports often do not distinguish between cleft lip, cleft palate, or both, but in our personal experience, among the cases collected from clinical geneticists in the UK, an isolated palatal cleft is the most frequent finding. Martinez-Frias ${ }^{15}$ suggested that oral clefts were only seen when valproate was used in combination with other anticonvulsants, but we know of two cases of cleft palate occurring after exposure to valproate alone.

Limb defects and digital abnormalities of various types are known to occur. The most frequently observed findings are of arachnodactyly with overlapping of the fingers and toes (fig 4). An underriding third toe is a common finding. The musculature of the lower limbs often appears to be rather poorly developed.

Other significant reports include the association of radial ray defects with FVS. ${ }^{419-21}$ These have included a short or absent radius, absent or triphalangeal thumb, and preaxial polydactyly. The radial ray defects are reproducible in animal models exposed to valproate in utero. It has been suggested that they only occur in patients exposed to large doses of valproate but the evidence for this is inconclusive. We have personally seen a pair of sibs born to a mother who took $1.2 \mathrm{~g}$ valproate per day while pregnant. This is not considered to be a large dose during pregnancy but both sibs were born with the typical fetal valproate facies and radial ray defects (figs 5 and 6). Other reported limb abnormalities include talipes deformity of the feet, clinodactyly, and ulnar or tibial hypoplasia.

\section{Counselling in FVS}

Information regarding the incidence of fetal valproate syndrome has mainly been derived from cases reported to birth defects registries ${ }^{1722}$ and as such is often biased. Overall, these studies suggest that there is a six to seven fold increase of malformations in the babies of mothers exposed to valproate compared to the general population. In a more recent study, Thisted and Ebbesen ${ }^{13}$ studied all infants born to epileptic mothers treated with valproate in the north of Denmark over a 
two year period. None of these pregnancies had been exposed to other recognised teratogens such as alcohol. There were 17 pregnancies in total: 11 of the infants required admission to a special care baby unit because of withdrawal symptoms, nine had minor dysmorphic features consistent with FVS, and five had a major congenital malformation. The effects were dose related and were seen when the mothers were taking in excess of $2.5 \mathrm{~g}$ valproic acid daily. Although the numbers are not large this study suggests that the risk to fetuses exposed to valproate is significant, with the majority showing some adverse effects. Chitayat $e t a l^{23}$ reported FVS in two sibs and we have personal experience of three other sib pairs. The risk of recurrence of FVS in a subsequent pregnancy exposed to valproate would therefore appear to be high, possibly owing to inherent problems with the metabolism of valproic acid in the mothers concerned. Data on the long term follow up of exposed people remain to be collected.

1 Dieterich E, Steveling A, Lukas A, Seyfeddinpur N, Spranger J. Congenital anomalies in children of epileptic mothers and fathers. Neuropediatrics 1980;11:274-83.

2 Hanson JW, Smith DW. The fetal hydantoin syndrome. $f$ Pediatr 1975;87:285-90

3 DiLiberti JH, Farndon PA, Dennis NR, Curry CJR. The fetal valproate syndrome. Am 7 Med Genet 1984;19:473-81.

4 Jager-Roman E, Deichl A, Jakob S, et al. Fetal growth, major malformations and minor anomalies in infants born to women receiving valproic acid. $\mathcal{F}$ Pediatr 1986;108: 997-1004.

5 Winter RM, Donnai D, Burn J, Tucker SM. Fetal valproate syndrome: is there a recognisable phenotype? 7 Med Genet 1987;24:692-5

6 Ardinger $\mathrm{HH}$, Atkin JF, Blackston RD, et al. Verification of the fetal valproate syndrome phenotype. Am $\mathcal{F}$ Med Genet 1988;29:171-85.

7 Brown JK. Valproate toxicity. Dev Med Child Neurol 1988; 30:115-25.

8 Coulter DL. Carnitine, valproate and toxicity. $\mathcal{F}$ Child Neurol 1991;6:7-14.

9 Dalens B, Raynaud EJ, Gaulme J. Teratogenicity of valproic acid. $\mathcal{F}$ Pediatr 1980;97:332-3.

10 Robert E, Guibaud P. Maternal valproic acid and congenital neural tube defects. Lancet 1982;ii:1282-3.

11 Lindhout D, Schmidt D. In utero exposure to valproate and neural tube defects. Lancet 1986;i:1392-3.

12 Martinez-Frias ML, Salvador J, Rodriquez-Pinilla E. Valproate and spina bifida. Lancet 1989;i:611-12.

13 Thisted E, Ebbeson F. Malformations, withdrawal manifestations and hypoglycaemia after exposure to valproate in utero. Arch Dis Child 1993;69:288-91.

14 Felding I, Rane A. Congenital liver damage after treatment of mother with valproic acid and phenytoin? Acta Paediatr Scand 1984;73:565-8

15 Martinez-Frias ML. Clinical manifestation of prenatal exposure to valproic acid using case reports and epidemiologic information. Am 7 Med Genet 1990;37: 277-82.

16 Van Allen MI, Kalousek DK, Chernoff GF, et al. Evidence for multi-site closure of the neural tube in humans. $\operatorname{Am} \mathcal{F}$ Med Genet 1993;47:723-43.

17 Robert E, Rosa F. Valproate and birth defects. Lancet 1983; ii: 1142 .

18 Hurd RW, Wilder BJ, Van Rinsvelt HA. Valproate, birth defects and zinc. Lancet 1983;i: 181 .

19 Huot C, Gauthier M, Lebel M, Larbrisseau A. Congenital malformations associated with maternal use of valproic malformations associated with maternal

20 Verloes A, Frikiche A, Gremillet C, et al. Proximal phocomelia and radial ray aplasia in fetal valproic syndrome. Eur $\mathcal{F}$ Pediatr 1990;149:266-7.

21 Sharony R, Garber A, Viskochil D, et al. Preaxial ray reduction defects as part of valproic acid embryofetopathy. Prenat Diagn 1993;13:909-18.

22 Mastroiacovo P, Bertolini R, Morandini S, Segni G. Maternal epilepsy, valproate exposure and birth defects. Lancet 1983;ii: 1499 .

23 Chitayat D, Farrell K, Anderson L, Hall JG. Congenital abnormalities in two sibs exposed to valproic acid in utero. Am $\mathcal{F}$ Med Genet 1988;31:369-73. 